\title{
Cell Type-Specific Expression of Acid-Sensing Ion Channels in Hippocampal Interneurons
}

\author{
Ju-Yun Weng, Yen-Chu Lin, and Cheng-Chang Lien \\ Institute of Neuroscience and Brain Research Center, National Yang-Ming University, Taipei 112, Taiwan
}

Acid-sensing ion channels (ASICs), a member of the degenerin/epithelial $\mathrm{Na}^{+}$channel superfamily, are widely expressed in the mammalian CNS. Accumulating evidence suggests that ASIC current density is higher in GABAergic interneurons than that in glutamatergic pyramidal neurons (PNs) in the hippocampus. Such differential expression of ASICs in cortical networks is thought to be a key element for seizure termination. However, GABAergic interneurons are highly diverse; it is unclear whether the functional expression of ASICs differs in distinct GABAergic interneuron subtypes. Moreover, the subunit composition of ASICs in individual GABAergic interneurons remains unknown. By combining patch-clamp recording and single-cell reverse transcription (RT)-PCR analysis, we correlated ASIC currents with their gene expression in acute rat hippocampal slices. The results yielded several surprising findings. First, ASIC current density of oriens lacunosum-moleculare (0-LM) cells in the CA1 region, a classical type of dendrite-targeting interneuron, is 6 times greater than that of fast-spiking basket cells $(\mathrm{BCs})$ in the dentate gyrus, a major class of soma-targeting interneuron. Second, the recovery of ASICs from desensitization is slowest in BCs, intermediate in PNs, and fastest in 0-LM cells. Third, the tarantula venom psalmotoxin 1, the specific blocker for ASIC1a homomers, inhibits ASIC currents in BCs but not in 0-LM cells. Finally, single-cell RT-PCR analysis reveals coexpression of ASIC1a and ASIC2 subunit transcripts in 0-LM cells, whereas only ASIC1a subunit transcript is detected in most BCs. Thus, differential expression of ASICs in inhibitory microcircuits likely contributes to the distinct roles of GABAergic interneurons in normal physiology and pathophysiology.

\section{Introduction}

Acid-sensing ion channels (ASICs), a member of the degenerin/ epithelial $\mathrm{Na}^{+}$channel (DEG/ENaC) cation channel superfamily, are widely expressed in the mammalian nervous system (Waldmann et al., 1997; for review, see Wemmie et al., 2006) and have been implicated in pain, ischemic stroke, seizures and many other neurological diseases (Xiong et al., 2004; Mazzuca et al., 2007; Ziemann et al., 2008; Coryell et al., 2009). Many studies showed that GABAergic inhibitory interneurons in the hippocampus have larger ASIC current densities than glutamatergic excitatory pyramidal neurons (PNs) (Bolshakov et al., 2002; Cho and Askwith, 2008; Ziemann et al., 2008). In line with this view, a recent report showed that ASICla null mice display delayed seizure termination after seizure induction and suggested that ASIC activation by falls in extracellular $\mathrm{pH}$ during seizures increases the cortical inhibition through preferential recruitment of GABAergic inhibitory interneurons (Ziemann et al., 2008).

However, GABAergic inhibitory interneurons consist of a highly heterogeneous population of cells (McBain and Fisahn,

Received Jan. 5, 2010; revised Feb. 24, 2010; accepted March 21, 2010.

This work was supported by Yen Tjing Ling Medical Foundation (CI-96-4), Ministry of Education (Aim for The Top University Grant) in Taiwan, National Health Research Institutes (Grants NHRI-EX97-9720NC), and Taiwan National Science Council (Grant 98-2321-B-010-001). We thank Dr. P. Jonas for invaluable comments on initial experiments, Dr. C. C. Askwith for providing ASIC recovery data, Drs. P. Jonas, T. C. Hwang, M. M. Poo, and C. P. Hung for critically reading the manuscript, and Dr. M. Martina for helpful advice.

Correspondence should be addressed to Dr. Cheng-Chang Lien, Institute of Neuroscience and Brain Research Center, National Yang-Ming University 155, Section 2, Li-Nong Street, Taipei 112, Taiwan. E-mail: cclien@ym.edu.tw. DOI:10.1523/JNEUROSCI.0582-10.2010

Copyright $\odot 2010$ the authors $\quad 0270-6474 / 10 / 306548-11 \$ 15.00 / 0$
2001; Jonas et al., 2004; Markram et al., 2004; Klausberger and Somogyi, 2008). Different GABAergic interneuron types have specific roles in hippocampal function (Klausberger and Somogyi, 2008). At least two functionally distinct classes of GABAergic interneurons are known to exist in the hippocampus (McBain and Fisahn, 2001; Jonas et al., 2004; Freund and Katona, 2007). Soma-targeting inhibitory interneurons, such as fast-spiking basket cells (BCs), control the spike initiation of principal neurons via axonal innervations onto perisomatic areas of principal neurons (Cobb et al., 1995; Miles et al., 1996; Kraushaar and Jonas, 2000), whereas dendrite-targeting inhibitory interneurons, such as oriens lacunosum-moleculare (O-LM) cells, regulate dendritic $\mathrm{Na}^{+}$or $\mathrm{Ca}^{2+}$ spikes and synaptic plasticity by innervating dendritic domains of principal neurons (Miles et al., 1996). These two distinct GABAergic interneuron subtypes differ not only in their intrinsic properties, such as neurochemical contents, $\mathrm{Ca}^{2+}$ buffering proteins/homeostasis, ion channels, and transmitter receptors (Koh et al., 1995; Freund and Buzsáki, 1996; Martina et al., 1998; Lien et al., 2002; Pouille and Scanziani, 2004; Aponte et al., 2008; Liao and Lien, 2009), but also in their synaptic and network functions (Klausberger et al., 2003; Pouille and Scanziani, 2004; Klausberger and Somogyi, 2008). Unfortunately, the lack of measurement of ASIC currents from identified GABAergic inhibitory interneurons has left a fundamental question unresolved: is the ASIC expression among hippocampal GABAergic inhibitory interneurons cell type-specific? Moreover, the subunit composition of ASICs in various classes of GABAergic inhibitory interneurons ("perisomatic" versus "dendritic" interneurons) remains to be determined. 
In this study, we correlated the functional property with geneexpression profile of ASICs in the PNs in the CA1 region and two functionally distinct classes of GABAergic inhibitory interneurons-O-LM cells and fast-spiking BCs in rat hippocampal slices by combining patch-clamp techniques and single-cell reverse transcription (RT)-PCR (Lien et al., 2002; Liss et al., 2004). Using these approaches, we uncovered a previously unknown expression pattern of ASICs in GABAergic inhibitory microcircuits, which likely underlies the selective vulnerability of distinct types of GABAergic inhibitory interneurons under pathological conditions.

\section{Materials and Methods}

Patch-clamp techniques in hippocampal slices. Transverse hippocampal slices of $300 \mu \mathrm{m}$ thickness were cut from the brains of 15- to 23-d-old male Sprague Dawley rats using a vibratome (DSK-1000, Dosaka) as described previously (Lien et al., 2002; Liao and Lien, 2009). Animals were sacrificed by decapitation in agreement with national and institutional guidelines and all procedures were approved by the Animal Care and Use Committee of National Yang-Ming University. Slices were sectioned in the ice-cold cutting saline containing the following (in $\mathrm{mM}$ ): 87 $\mathrm{NaCl}, 25 \mathrm{NaHCO}_{3}, 1.25 \mathrm{NaH}_{2} \mathrm{PO}_{4}, 2.5 \mathrm{KCl}, 10$ glucose, 75 sucrose, 0.5 $\mathrm{CaCl}_{2}$ and $7 \mathrm{MgCl}_{2}$. Following sectioning, slices were incubated in the cutting saline (oxygenated with $95 \% \mathrm{O}_{2} / 5 \% \mathrm{CO}_{2}$ ) in a holding chamber at $34^{\circ} \mathrm{C}$ for $30 \mathrm{~min}$, and then at room temperature until used. During experiments, an individual slice was transferred to a submersion recording chamber and was continuously superfused with oxygenated artificial CSF containing the following (in mM): $125 \mathrm{NaCl}, 25 \mathrm{NaHCO}_{3}, 1.25$ $\mathrm{NaH}_{2} \mathrm{PO}_{4}, 2.5 \mathrm{KCl}, 25$ glucose, $2 \mathrm{CaCl}_{2}$ and $1 \mathrm{MgCl}_{2}$.

Experiments were performed under visual control using infrared differential interference contrast (IR-DIC) videomicroscopy (Stuart et al., 1993). O-LM cells in the CA1 subfield were selected based on the following criteria (Lien et al., 2002; Liao and Lien, 2009): (1) location of a fusiform soma in the stratum oriens with bipolar dendrites; (2) a pronounced sag response upon 1 s hyperpolarizing current pulse $(-300 \mathrm{pA})$ injection; (3) fast-spiking patterns $(50-60 \mathrm{~Hz})$ and pronounced fast afterhyperpolarization during $1 \mathrm{~s}$ depolarization. For CA1 pyramidal neuron recording, cells of large somata in the stratum pyramidale with accommodating firing patterns were chosen. Dentate gyrus (DG) BCs were selected in accordance with previous reports (Koh et al., 1995; Martina et al., 1998; Aponte et al., 2008): (1) a relatively large size of cell body near the border between granule cell layer and hilus; (2) high-frequency $(\geq 70 \mathrm{~Hz}$ ) action potential (AP) phenotype; (3) relatively low input resistance $(<170 \mathrm{M} \Omega)$; (4) little sag response upon membrane hyperpolarization. The recording temperature was $22-24^{\circ} \mathrm{C}$.

Nucleated patch recordings. Nucleated patch recordings were made as described previously (Lien et al., 2002; Lien and Jonas, 2003) using an Axopatch 200B amplifier (Molecular Devices). Pipette capacitance was compensated. Signals were low-pass filtered at $5 \mathrm{kHz}$ (four-pole Bessel), and sampled at 10 $\mathrm{kHz}$ using a digitizer Digidata 1322A (Molecular Devices). Pulse sequences were generated by Digidata 1322A via pClamp 9.2 (Molecular Devices). Minor and major axes of nucleated patches were measured. It was assumed that nucleated patches were approximately ellipsoid (Gentet et al., 2000) and the membrane surface area was calculated using the following formula:

$$
\text { Surface area }=(\text { major axis }+ \text { minor axis })^{2}(\pi / 4)
$$

Fast application of $\mathrm{H}^{+}$. Fast application of $\mathrm{H}^{+}$on nucleated patches isolated from identified neurons was performed as described previously (Koh et al., 1995). Fast application experiments were started 1-2 min after the patches were excised. Double-barreled application pipettes were fabricated from theta glass capillaries ( $2 \mathrm{~mm}$ outer diameter, $0.3 \mathrm{~mm}$ wall thickness, $0.12 \mathrm{~mm}$ septum, Hilgenberg $\mathrm{GmbH}$ ), and mounted on a piezoelectric-based solution switching system (Burleigh LSS-3000, EXFO). The time necessary for complete exchange of solution was measured with an open patch pipette by switching between $\mathrm{Na}^{+}$-rich and $20 \% \mathrm{Na}^{+}$-rich solutions. It was $227 \pm 50 \mu \mathrm{s}(n=3)$ by measuring $20-80 \%$ rise time of junction potential change. ASIC currents evoked by
$2 \mathrm{~s}$ pulses of $\mathrm{H}^{+}$were applied every 15-30 s except in some pharmacological experiments (see Fig. 5), short pulses (50 ms) were used.

Focal $\mathrm{H}^{+}$puffing to dendrites. To visualize dendrites, we filled neurons with red fluorescent dye sulforhodamine 101 (SR101; $10 \mu \mathrm{M}$ ) via somatic recording. The dendrites were traced under epifluorescence microscope. To evoke ASIC currents along the dendrites, the puffing pipette was placed close to the dendrites (see Fig. 7). Voltage changes or ASIC currents were evoked by focal puffs of $\mathrm{H}^{+}(\sim 6 \mathrm{psi})$ using PicoSpritzer III (Parker Instrumentation) in whole-cell current or voltage-clamp recording. Acidic $\mathrm{pH}$ solution was injected via a patch pipette with an open tip $(2 \mu \mathrm{m})$. The PicoSpritzer was triggered by an external TTL pulse generated by Digidata 1322A. This approach approximates the ASIC current amplitudes at dendrites and the caveat should be pointed out here. It is clear that the current amplitude did not directly reflect channel density because the surface area exposed to the puff varied.

Morphological analysis. Morphological reconstruction was identical to those reported previously (Liao and Lien, 2009). A separate subset of CA1 pyramidal cells, O-LM cells and BCs were filled with biocytin $(0.2 \%)$ during recordings. After $\sim 30$ min recording, slices were fixed overnight with $4 \%$ paraformaldehyde in phosphate-buffered solution (PB; $0.1 \mathrm{M}$, $\mathrm{pH}$ 7.3). Following wash with $\mathrm{PB}$, slices were incubated with fluorescein isothiocyanate (FITC)-conjugated avidin-d ( $2 \mu \mathrm{l} / \mathrm{ml}$; Invitrogen) in PB and $0.3 \%$ Triton X-100 overnight at $4^{\circ} \mathrm{C}$. After wash, slices were embedded in mounting medium Vectashield (Vector Laboratories). Labeled cells were examined by a two-photon microscope using a pulsed titanium/sapphire laser (Chameleon-Ultra II tuned to $800 \mathrm{~nm}$; Coherent) attached to a Leica DM6000 CFS that was equipped with a $20 \times / 0.50$ numerical aperture water-immersion objective (HCX APO L; Leica). The two dimensional morphologies of the cells were reconstructed from a stack of $38-455$ images (voxel size, $0.378-1.514 \mu \mathrm{m}$ in the $x-y$ plane; $0.4-0.99 \mu \mathrm{m}$ along the $z$-axis) using ImageJ (v. 1.42q).

Solutions and drugs. The HEPES-buffered $\mathrm{Na}^{+}$-rich external solution used for fast application in the control barrel contained (in $\mathrm{mM}$ ): 135 $\mathrm{NaCl}, 5.4 \mathrm{KCl}, 1.8 \mathrm{CaCl}_{2}, 1 \mathrm{MgCl}_{2}, 5 \mathrm{HEPES}$; $\mathrm{pH}$ adjusted to 7.4 with $\mathrm{N}$-methyl-D-glucamine (NMDG). To evoke ASIC currents with various $\mathrm{pH}$ values, MES-buffered $\mathrm{Na}^{+}$-rich external solution in the test barrel contained (in mM): $135 \mathrm{NaCl}, 5.4 \mathrm{KCl}, 1.8 \mathrm{CaCl}_{2}, 1 \mathrm{MgCl}_{2}, 10 \mathrm{MES}$, adjusted to the desired values with NMDG. The intracellular solution contained (in $\mathrm{mM}$ ): $135 \mathrm{~K}$-gluconate, $20 \mathrm{KCl}, 0.1 \mathrm{EGTA}, 2 \mathrm{MgCl}_{2}, 4$ $\mathrm{Na}_{2}$ ATP, 10 HEPES; $\mathrm{pH}$ adjusted to 7.3 with $\mathrm{HCl}$. For low $\mathrm{Na}^{+}$experiments, $\mathrm{Na}^{+}$in the buffered $\mathrm{Na}^{+}$-rich external solution was substituted by NMDG. For low $\mathrm{Na}^{+} /$high $\mathrm{Ca}^{2+}$ experiments, concentrations of $\mathrm{NaCl}$ and $\mathrm{CaCl}_{2}$ were varied as indicated (see Fig. $3 C$ ). Bovine serum albumin $(0.1 \%)$ was added in external solutions containing the spider toxin Psalmotoxin 1 (PcTX1; Peptides International) to prevent its absorption to tubing and containers. Amiloride from Tocris Bioscience was dissolved in water to give $10 \mathrm{~mm}$ stock solution and stored at $-20^{\circ} \mathrm{C}$. All other chemicals were from Sigma except where noted.

Data analysis and statistics. Data were analyzed and fitted with Clampfit 10.0 (Molecular Devices) and Mathematica 5.2 (Wolfram Research). Apparent input resistance was defined by the ratio of peak voltage change/1 s hyperpolarizing current $(-100 \mathrm{pA})$. Desensitization and deactivation time constants of ASIC currents were obtained by fitting currents with the function:

$$
I(t)=\frac{-t}{A e^{\tau_{\text {decay }}}}+\mathrm{C}
$$

where $A$ denotes the peak amplitude of current, $\tau_{\text {decay }}$ represents the desensitization or deactivation time constant, and $C$ denotes the amplitude of steady-state current.

Concentration-response curves were fitted with the function:

$$
f(c)=\frac{A}{\left[1+\left(\frac{\mathrm{EC}_{50}}{c}\right)^{n}\right]}
$$

where $A$ is the constant for the maximal effect, $c$ denotes the concentration, $\mathrm{EC}_{50}$ represents the half-maximal effective concentration, and $n$ denotes the Hill coefficient. 
For measuring reversal potential, data points of $I-V$ relations (see Fig. $3 B$ ) were fitted with second order polynomials, from which the interpolated potentials were calculated. Theoretical reversal potential of sodium channels $\left(E_{\text {rev }}\right)$ was plotted against external $\mathrm{Na}^{+}$concentration according to the Nernst equation:

$$
E_{\text {rev }}=\frac{R T}{F} \ln \frac{\left[\mathrm{Na}^{+}\right]_{\mathrm{O}}}{\left[\mathrm{Na}^{+}\right]_{\mathrm{i}}}
$$

where $\left[\mathrm{Na}^{+}\right]_{\mathrm{o}},\left[\mathrm{Na}^{+}\right]_{\mathrm{i}}$ are outer and inner $\mathrm{Na}^{+}$concentrations and $F, R$, $T$ have standard thermodynamic meanings (Hille, 2001).

The single-channel conductance of ASIC was estimated by nonstationary fluctuation analysis (Hartveit and Veruki, 2007) of ASIC currents from 23 to 50 traces (see Fig. 6A). To minimize errors due to rundown, the entire dataset was divided into nonoverlapping subsets of 7-10 traces (Engel and Jonas, 2005). Mean ensemble current and variances were determined for each subset and averaged. Mean variance $\left(\sigma^{2}\right)$ versus mean current $(I)$, for each sampling point, can then be obtained. To assign similar weights to all phases of the ensemble mean waveform, binning of mean $I$ and corresponding $\sigma^{2}$ were used by dividing the mean current amplitude into a number of bins of equal amplitude (Hartveit and Veruki, 2007). The values of mean $I$ and mean $\sigma^{2}$ within each bin were then further averaged. The averaged mean $I$ was plotted against the averaged mean $\sigma^{2}$ and then fitted with the equation when they look like a parabola:

$$
\sigma^{2}(I)=i I-\frac{I^{2}}{N}+\sigma_{\mathrm{b}}^{2}
$$

developed from a binomial model, yielding values for apparent singlechannel current $i$, total number of ion channel $N$ available for activation. $\sigma_{\mathrm{b}}^{2}$ is the variance of the background noise. In all BCs $(n=5)$ and some PNs ( 3 of 7), the data can be adequately described with a straight line rather than a parabola. The slope of the variance-mean relation was plotted with the equation:

$$
\sigma^{2}(I)=i I+\sigma_{\mathrm{b}}^{2}
$$

The single-channel chord conductance $\gamma$ was calculated as follows:

$$
\gamma=\frac{i}{\left(V_{\mathrm{m}}-E_{\mathrm{rev}}\right)}
$$

The maximum open probability $\left(P_{\mathrm{o}, \max }\right)$, corresponding to the fraction of available ion channels open at the time of the peak current $\left(I_{\text {peak }}\right)$, can then be calculated from the following equation:

$$
P_{\mathrm{o}, \max }+\frac{I_{\text {peak }}}{i N}
$$

Values indicate mean \pm SEM; error bars in figures also represent SEM. Statistical significance among groups was tested using the nonparametric Kruskal-Wallis test. When it was significant, pairwise comparisons by the Wilcoxon rank-sum test were then carried out for each pair of groups. All tests were performed at the significance level $(P)$ indicated using GraphPad Prism 5.0. SEs of reversal potentials were obtained by analyzing data of individual experiments separately. SEs of parameters of doseresponse curves were calculated by a parametric bootstrap method (Efron and Tibshirani, 1998). A total of 500 artificial datasets were generated in which the original values were replaced by normally distributed random numbers with means and SEM identical to those of the original data points, and were fitted as the original dataset.

Single-cell RT-PCR. Single-cell gene expression profiles were analyzed using the single-cell RT-PCR approach as previously described (Martina et al., 1998; Lien et al., 2002; Liss and Roeper, 2004; Aponte et al., 2006). RNase-free patch-clamp buffer containing (in $\mathrm{mm}$ ): $140 \mathrm{KCl}, \mathrm{MgCl}_{2}, 5$ HEPES, 5 EGTA ( $\mathrm{pH}=7.3$ ) was autoclaved before used. Patch-clamp capillaries were baked overnight at $220^{\circ} \mathrm{C}$ before use. The cytoplasm of a

\begin{tabular}{|c|c|c|}
\hline Gene & Forward/Reverse & Product size (bp) \\
\hline Parvalbumin & $\begin{array}{l}5^{\prime} \text {-GGCGATAGGAGCCTTTACTGCTGC-3' } \\
5^{\prime} \text {-GAAACCCAGGAGGGCCGCGA-3' }\end{array}$ & 372 \\
\hline Somatostatin & $\begin{array}{l}5^{\prime} \text {-GGCTGCCACCGGGAAACAGGAAC-3' } \\
5^{\prime} \text {-CCTGCTCAGCTGCCTGGGGC-3' }\end{array}$ & 119 \\
\hline Calcineurin & $\begin{array}{l}5^{\prime} \text {-CCGAGCCCACGAAGCCCAGG-3' } \\
5^{\prime} \text {-TGCAGCCGTGGCTCCGTCAA-3' }\end{array}$ & 337 \\
\hline GAD65 & $\begin{array}{l}\text { 5'-TGGCATCTCCGGGCTCTGGCT-3' } \\
\text { 5'-TGGCAGCAGGTCTGTTGCGTGG-3' }\end{array}$ & 296 \\
\hline Neurofilament 3 & $\begin{array}{l}5^{\prime} \text {-TGGCCGCATATAGGAAACTACTG-3' } \\
5^{\prime} \text {-GGGCTGTCGGTGTGTGTACA-3' }\end{array}$ & 95 \\
\hline Cholecystokinin & $\begin{array}{l}\text { 5'-GCTGGACAGCAGCCGTTGGA-3' } \\
5^{\prime} \text {-GGCCAGAGGGAGCTTTGCGG-3' }\end{array}$ & 280 \\
\hline ASIC1a & $\begin{array}{l}\text { 5'-GAACATTCTGGTGCTGGACATT-3' } \\
5^{\prime} \text {-CCTGTGCTTAATGACCTCGTAG-3' }\end{array}$ & 184 \\
\hline $\mathrm{ASIC}^{a}$ & $\begin{array}{l}\text { 5'-CGCACAACTTCTCCTCAGTGTTT-3' } \\
\text { 5'-GTACTCATCTTGCTGAATGTCCA-3' }\end{array}$ & 146 \\
\hline
\end{tabular}
recorded neuron was harvested into the recording pipette, under visual control, without losing the gigaseal immediately after electrophysiological characterization. The contents of the patch pipette
Table 1. Oligonucleotide primers for RT-PCR

${ }^{a} \mathrm{ASIC} 2 \mathrm{a}$ and $\mathrm{ASIC} 2 \mathrm{~b}$ mRNAs were detected with a pair of common primers.

$(\sim 2-5 \mu \mathrm{l})$ were expelled into a $0.2 \mathrm{ml}$ PCR tube (Axygen Scientific) containing $17 \mu \mathrm{l}$ of RT mix (SuperScript III platinum Two-Step qPCR Kit with SYBR green I, Invitrogen). The mix contained $5 \mu$ l of diethylpyrocarbonate (DEPC)-treated water, $10 \mu \mathrm{l}$ of $2 \times \mathrm{RT}$ reaction mix (oligo(dT) ${ }_{20}$, random hexamers, $\mathrm{MgCl}_{2}$ and dNTPs) and $2 \mu \mathrm{l}$ of RT enzyme mix (SuperScript III reverse transcriptase and recombinant ribonuclease inhibitor). Total volume was $\sim 20 \mu \mathrm{l}$. After a series of incubation at different temperatures according to the manufacturer's instructions, the cDNA-containing tube was stored at $-70^{\circ} \mathrm{C}$ until used. The RNA strand in the RNA-DNA hybrid was then removed by adding $1 \mu \mathrm{l}(2 \mathrm{U} / \mu \mathrm{l})$ of $E$. coli RNase $\mathrm{H}$ and incubated at $37^{\circ} \mathrm{C}$ for 20 min before PCR process.

Following cDNA synthesis, the cDNA solution of a single cell was split into 3 aliquots $(5 \mu \mathrm{l})$ and each of them was used for gene amplification. A PCR approach with Rotor-Gene 3000 (Corbett Research) or StepOnePlus Real-Time PCR system (Applied Biosystems) was performed in a total volume of $25 \mu \mathrm{l}$ with $1 \mu \mathrm{l}$ of $10 \mu \mathrm{m}$ primers (each), $5.5 \mu \mathrm{l}$ of DEPC-treated water and $12.5 \mu \mathrm{l}$ of Platinum SYBR Green qPCR SuperMix-UDG (Invitrogen) containing Platinum TaqDNA polymerase, $\mathrm{Mg}^{2+}$, uracil DNA glycosylase, proprietary stabilizers, and dNTPs with dUTP. Primers were designed with Perlprimer v1.1.14 and selected for maximal specificity and intron-overspanning amplicons (Table 1). The molecular weights of the ASIC1a and ASIC2 amplicons and other neuron-specific markers were subsequently examined on ethidium bromide-stained agarose gels; sizes were in close agreement with the expected lengths (see Fig. 4A). For ASIC expression profiles, all analyzed neurons expressed neurofilament 3 (NF3), indicating selective harvesting from neurons. To exclude the possibility of contaminations, no template control was performed in parallel to every PCR, and the reverse transcriptase was omitted in a subset of cells. Additional controls to exclude nonspecific harvesting were performed by advancing pipettes into the slice and taking them out without seal formation and suction (Martina et al., 1998; Lien et al., 2002).

\section{Results}

Functional ASICs are differentially expressed in hippocampal microcircuits

We made whole-cell patch recordings from neurons in acute rat hippocampal slices under IR-DIC optics (Fig. 1A). Neurons in the CA1 area and the DG were selected as previously described (Martina et al., 1998; Lien and Jonas, 2003; Aponte et al., 2008; Liao and Lien, 2009). Under current-clamp configuration at $23 \pm$ $1^{\circ} \mathrm{C}$, CA1 PNs generated regular and accommodating AP trains upon injection of $1 \mathrm{~s}$ depolarizing current $(+600 \mathrm{pA})$ pulses and exhibited sag responses in response to $1 \mathrm{~s}$ hyperpolarizing current $(-300 \mathrm{pA})$ pulses with apparent input resistance of $176 \pm 9.1$ $\mathrm{M} \Omega(n=30$, Fig. $1 A$, middle). Under the same protocol, O-LM 
A
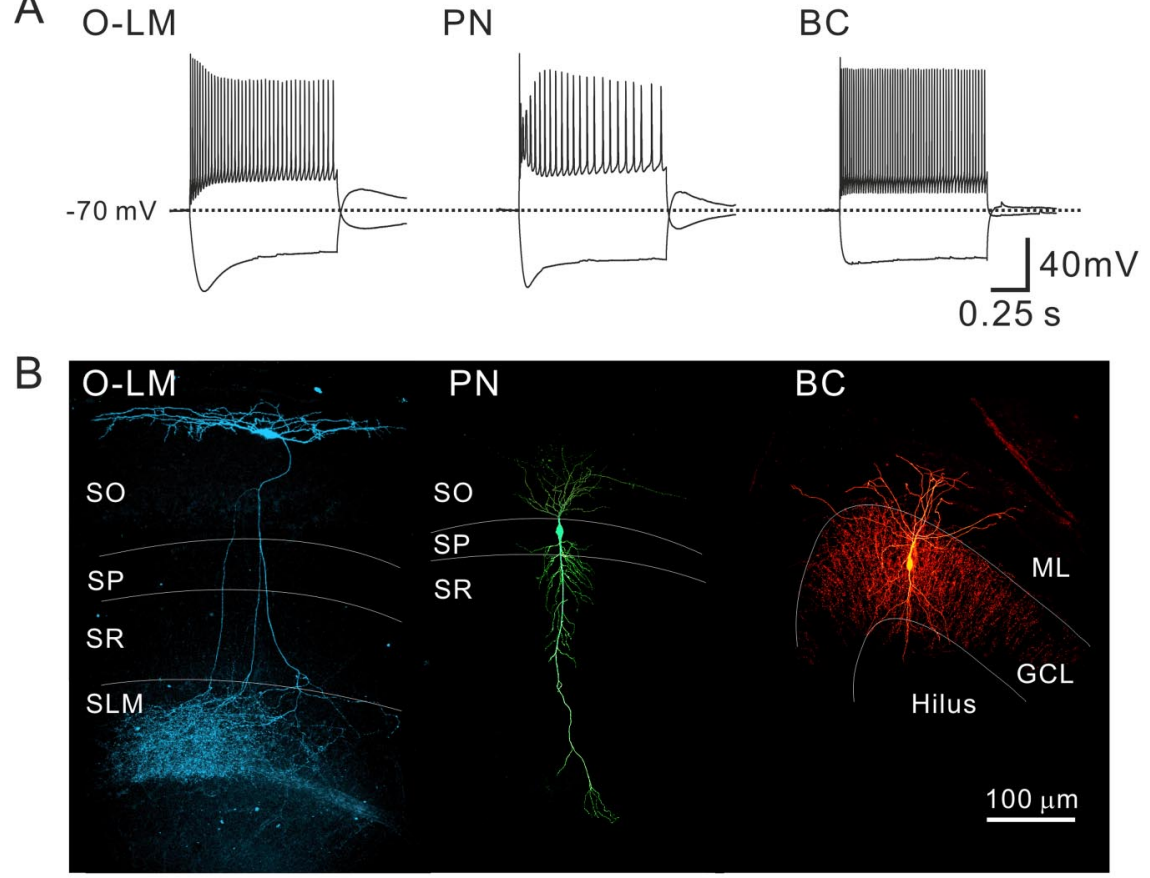

C
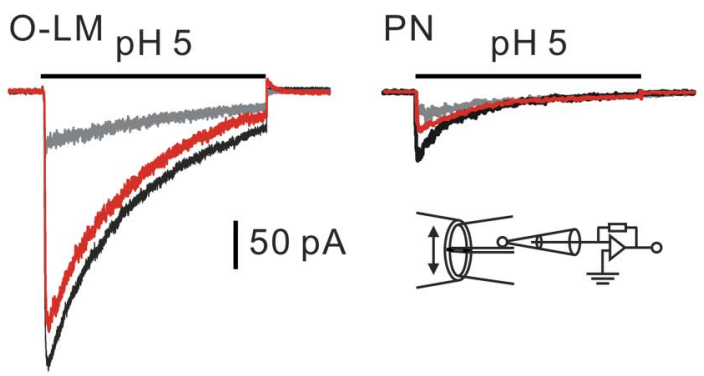

$\mathrm{BC}$
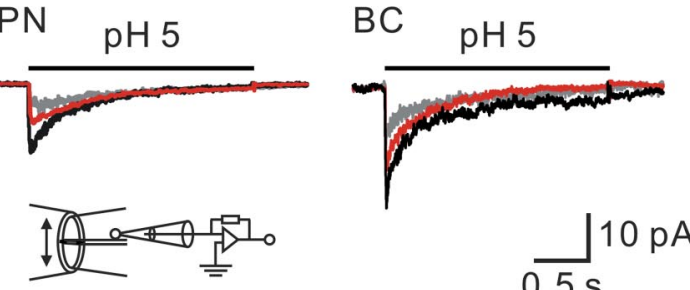

D
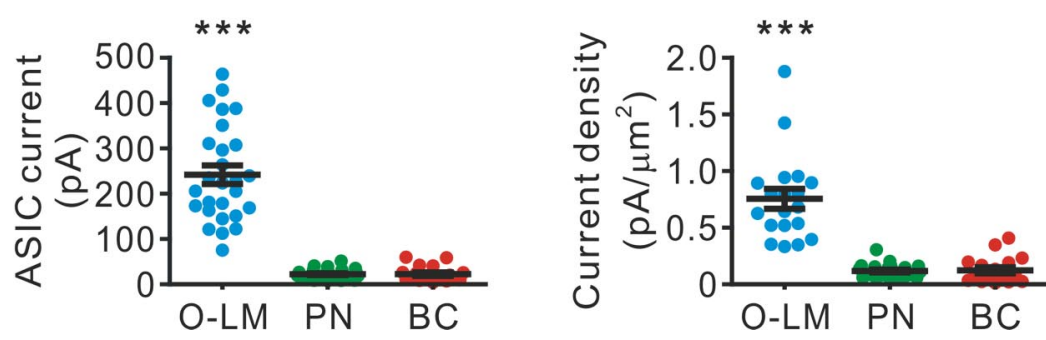

Figure 1. ASIC currents in CA1 PNs and defined interneurons. A, Voltage responses to $1 \mathrm{~s}$ depolarizing $(+600 \mathrm{pA})$ or hyperpolarizing $(-300 \mathrm{pA})$ current pulses in the whole-cell current-clamp configuration from an 0-LM cell, a PN and a $B C$, respectively. $\boldsymbol{B}$, Two-photon $z$ stack projection of neurons in $\boldsymbol{A}$ filled with biocytin and stained with FITC-conjugated avidin. Note that the 0 -LM cell has its axonal arborization in stratum lacunosum moleculare (SLM), whereas the $B C^{\prime}$ 's axon is largely restricted to the granule cell layer (GCL). SR, stratum radiatum; SP, stratum pyramidale; SO, stratum oriens; ML, molecular layer. C, Inward currents recorded at $-60 \mathrm{mV}$ after rapid $\mathrm{pH}$ changes from $\mathrm{pH} 7.4$ to 5 in nucleated patches from an 0 - $\mathrm{LM}$ cell, a PN and a BC, respectively. Traces are averages of 5-10 sweeps. $\mathrm{H}^{+}$-evoked currents are reversibly blocked by $10 \mu \mathrm{m}$ amiloride (control: black; amiloride: gray; washout: red). Inset, Schematic of the experimental configuration. The open tip response was $227 \pm 50 \mu s(n=3)$ (see Materials and Methods). D, Scatter plots showing that the current amplitude (left) and density (right) of 0 -LM cells are significantly larger than those of PNs and BCs. ${ }^{* * *} p<0.0005$.

cells generated APs at a frequency $\geq 50 \mathrm{~Hz}$ and showed pronounced sag responses with apparent input resistance of $335.6 \pm$ $25 \mathrm{M} \Omega(n=24$, Fig. $1 A$, left). In contrast to PNs and O-LM cells, BCs in the DG generated high-frequency AP trains $(86.7 \pm 2.9$ $\mathrm{Hz}, n=18$ ) with negligible sag responses and exhibited relatively low input resistance (133.9 $\pm 5 \mathrm{M} \Omega, n=18$; Fig. $1 A$, right). In a subset of experiments, the neuron types were further confirmed by post hoc morphological reconstruction of the recorded cells
(Fig. $1 B$ ) and cell type-specific markers (supplemental Fig. 1, available at www. jneurosci.org as supplemental material). Consistent with previous reports (Sík et al., 1998; Maccaferri et al., 2000; Klausberger et al., 2003), analyses of single-cell RT-PCR showed that CA1 PNs expressed calcineurin, whereas O-LM cells and BCs expressed somatostatin and parvalbumin, respectively (supplemental Fig. 1, available at www.jneurosci.org as supplemental material). Moreover, nucleated patches subsequently isolated from these three types of neurons after whole-cell recordings exhibited cell type-specific voltage-gated $\mathrm{K}^{+}$currents (Du et al., 1996; Martina et al., 1998; Lien et al., 2002). Total outward $\mathrm{K}^{+}$currents in nucleated patches from CA1 PNs consisted of a large proportion of A-type currents, whereas patches from O-LM cells or BCs exhibited a predominant sustained component (supplemental Fig. 2, available at www.jneurosci.org as supplemental material).

Extracellular $\mathrm{pH}$ reductions evoke ASIC currents in hippocampal PNs (Baron et al., 2002; Bolshakov et al., 2002; Askwith et al., 2004; Ziemann et al., 2008). We next measured ASIC currents in these neurons using nucleated patch configuration, which allowed us to examine channel gating under ideal voltage-clamp conditions. A submillisecond switch of extracellular $\mathrm{pH}$ from 7.4 to 5 by fast application induced a transient inward current of $22.3 \pm 1.9 \mathrm{pA}$ in CA1 PNs ( $n=27$, Fig. $1 C$, black, middle, Fig. $1 D$, left), corresponding to a current density of $0.11 \pm 0.01 \mathrm{pA} / \mu \mathrm{m}^{2}(n=27$; Fig. $1 D$, right). In contrast to CA1 PNs, nucleated patches from O-LM cells upon $\mathrm{pH} 5$ application exhibited a much larger current amplitude (237.9 $\pm 55.1 \mathrm{pA}, n=27$; Fig. $1 C$ black, left, Fig. $1 D$, left) with a current density of $0.75 \pm 0.08 \mathrm{pA} / \mu \mathrm{m}^{2}(n=19$; Fig. $1 D$, right). Surprisingly, the current amplitude (22.4 $\pm 3.8 \mathrm{pA}, n=19$; Fig. $1 C$, black, right, Fig. $1 D$, left) and density $\left(0.12 \pm 0.02 \mathrm{pA} / \mu \mathrm{m}^{2}, n=19\right.$; Fig. $1 D$, right) of nucleated patches from fast-spiking BCs in the DG were at least sixfold smaller than those of O-LM cells $(p<0.001$, Wilcoxon rank-sum test) but were comparable to those of CA1 PNs $(p=0.47$, Wilcoxon rank-sum test; Fig. 1D). All inward currents of these three cell types were reversibly blocked by the DEG/ $\mathrm{ENaC}$ channel inhibitor amiloride $(10 \mu \mathrm{M})$ (Fig. $1 C$, amiloride, gray; washout, red).

Non-fast-spiking interneurons in the DG have relatively large ASIC currents

We next investigated whether the feature of low ASIC current is unique to fast-spiking (FS) cells. In the DG, we classified all re- 
corded non-fast-spiking interneurons into two functional groups (stuttering and accommodating) based on their firing patterns (Markram et al., 2004) (Fig. $2 A)$. Nucleated patches from both stuttering (STUT) and accommodating (AC) interneurons had significantly larger ASIC currents than FS BCs (Fig. $2 B, C$ ). Overall, the ASIC currents in STUT and AC interneurons were $406 \pm 56 \mathrm{pA}(n=10)$ and $399 \pm 36 \mathrm{pA}(n=15)$, respectively (Fig. $2 C)$. Also, both STUT and AC interneurons had higher input resistance than FS BCs. The scatter plot of the ASIC current against the input resistance revealed that FS BCs are featured by relatively low input resistance and low ASIC currents (Fig. 2D).

\section{ASIC gating is dependent on cell type}

Steep $\mathrm{pH}$ dependence, $\mathrm{Na}^{+}$selectivity, and blockade by amiloride and extracellular $\mathrm{Ca}^{2+}$ ions are hallmark properties of ASIC gating (Waldmann et al., 1997; Bolshakov et al., 2002; Immke and McCleskey, 2003; Askwith et al., 2004; Wemmie et al., 2006; Cho and Askwith, 2008; Ziemann et al., 2008). To test pH dependence, we recorded ASIC currents upon different extracellular $\mathrm{pH}$ reductions. As represented by Figure $3 A$, the magnitude of ASIC current in an O-LM cell depended on the $\mathrm{pH}$ value. The doseresponse curve was fitted with the equation (Eq. 3), yielding the $\mathrm{pH}$ value of $6.0 \pm 0.0$ for the half-maximal activation and the Hill coefficient of $1.2 \pm 0.0$. We further determined the ionic permeability of ASICs by measuring the reversal potentials $\left(E_{\text {rev }}\right)$ in the presence of varied $\left[\mathrm{Na}^{+}\right]_{\mathrm{o}}$. ASIC currents in the normal condition $\left(\left[\mathrm{Na}^{+}\right]_{\mathrm{o}} /\left[\mathrm{Na}^{+}\right]_{\mathrm{i}}=\right.$ $135 / 8 \mathrm{mM})$ reversed at $62 \pm 3 \mathrm{mV}(n=4$, Fig. $3 B$ ). The plot of $E_{\mathrm{rev}}$ against $\left[\mathrm{Na}^{+}\right]_{\mathrm{o}}$ revealed that the values of $E_{\text {rev }}$ measured in a variety of $\left[\mathrm{Ca}^{2+}\right]_{\mathrm{o}} /\left[\mathrm{Na}^{+}\right]_{\mathrm{o}}$ solutions were close to the Nernst equilibrium potential for $\mathrm{Na}^{+}$(Fig. 3C, gray line; also see Eq. 4). These results indicate that $\mathrm{Na}^{+}$is the major permeant ion for ASICs. In addition to the sensitivity to amiloride (Fig. 1C), extracellular $\mathrm{Ca}^{2+}$ was shown to compete with $\mathrm{H}^{+}$ for the ASIC activation site (Immke and McCleskey, 2003). Consistent with this notion, we found that high $\left[\mathrm{Ca}^{2+}\right]_{\mathrm{o}}(18 \mathrm{~mm})$ inhibited acid ( $\mathrm{pH}$ 5)-induced currents by $60 \pm 2.3 \%$ (supplemental Fig. 3, available at www.jneurosci.org as supplemental material).

ASIC1a is a principal subunit for a functional ASIC, whereas ASIC2 subunit plays a modulatory role in the gating of ASIC, such as desensitization and recovery from desensitization (Askwith et al., 2004). We thus explored the potential differences in ASIC subunit composition of these three neuron types by measuring the desensitization time constant $\left(\tau_{\text {desen }}\right)$, deactivation time constant $\left(\tau_{\text {deact }}\right)$ and the recovery from de-

C
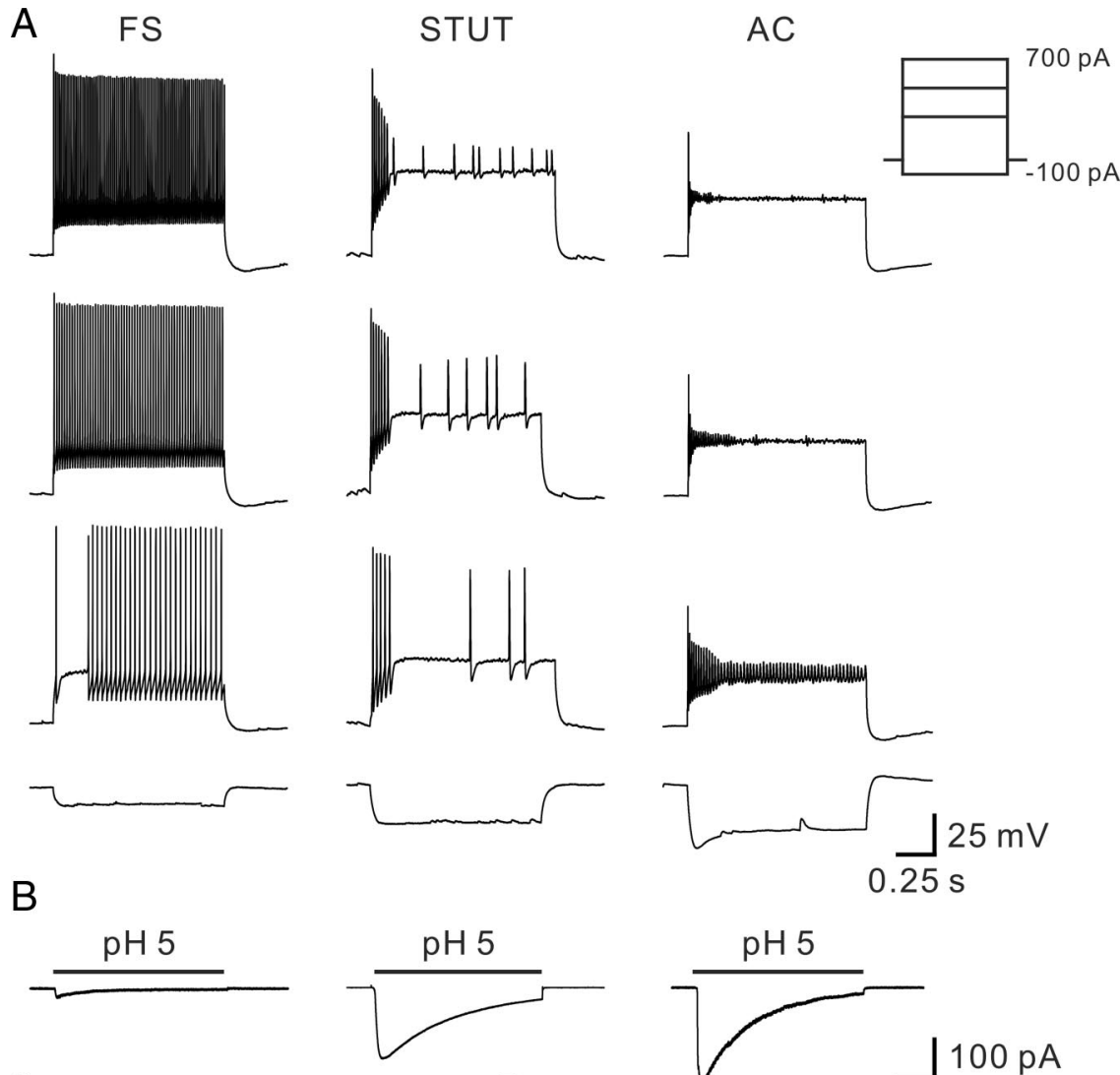

D
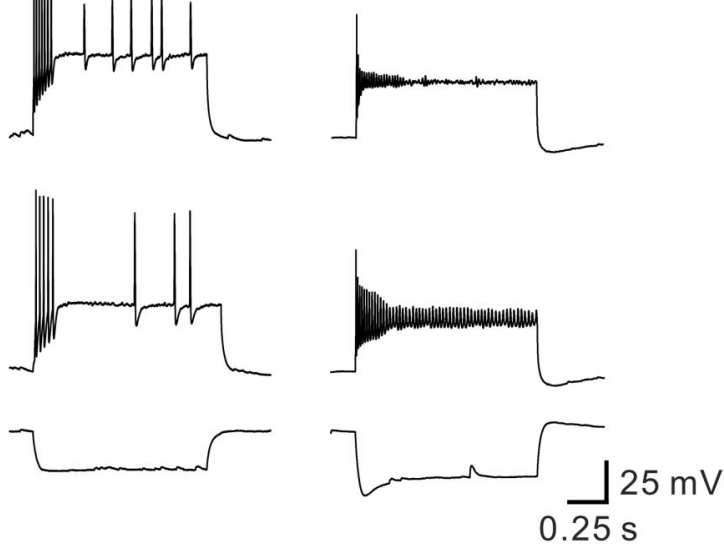

Figure 2. ASIC currents of various interneurons in the DG. $A$, Voltage responses to $1 \mathrm{~s}$ depolarizing $(+700,+500$ and $+300 \mathrm{pA})$ or hyperpolarizing $(-100 \mathrm{pA})$ current pulses in the whole-cell current-clamp configuration from a FS BC (left) and two non-FS protocol. $B$, Inward currents recorded at $-60 \mathrm{mV}$ after rapid $\mathrm{pH}$ changes from $\mathrm{pH} 7.4$ to $\mathrm{pH} 5$ in nucleated patches from a FS BC (left) (middle, STUT; right, AC) in the DG. Traces are average of 11-75 sweeps. C, Bar plot summarizing the amplitude of ASIC currents from FS BCS $(n=6)$, STUT $(n=10)$ and $A C(n=15)$ interneurons. ${ }^{* *} p<0.005 . D$, Scatter plot of the input resistance against the ASIC current from all FS and non-FS cells.

sensitization of ASIC currents. The $\tau_{\text {desen }}$ values of native ASICs from these three cell types were all $<1$ s (Fig. $3 D$ ). On the other hand, $\tau_{\text {deact }}$ values from three cell types were all $<10$ ms (Fig. $3 F)$. Notably, both $\tau_{\text {desen }}$ and $\tau_{\text {deact }}$ of ASICs in O-LM cells were significantly different from those of PNs and BCs. Interestingly, the recovery from desensitization as assessed by the recovery time constant $\left(\tau_{\text {recovery }}\right)$ was fastest $\left(\tau_{\text {recovery }}=\right.$ $0.96 \pm 0.00 \mathrm{~s})$ in O-LM cells, intermediate $\left(\tau_{\text {recovery }}=13.2 \pm\right.$ $0.1 \mathrm{~s})$ in CA1 PNs and slowest $\left(\tau_{\text {recovery }}=42.8 \pm 1.0 \mathrm{~s}\right)$ in BCs (Fig. $3 F$ ). Consistent with the recovery time course, cumulative desensitization of ASIC currents evoked by $0.05 \mathrm{~Hz}$ repetitive acid ( $\mathrm{pH} 5$ ) pulses was fastest in BCs, intermediate in PNs and slowest in O-LM cells (Fig. 3G). Together, these results strongly suggest differences in ASIC subunit composition among these three neuron types. 
A

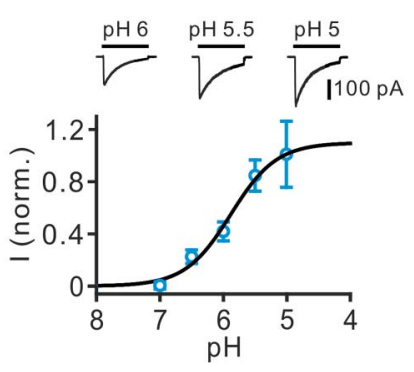

D

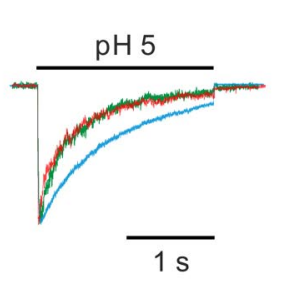

F

O-LM

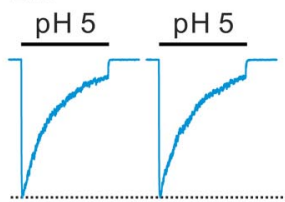

PN

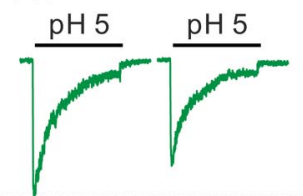

G

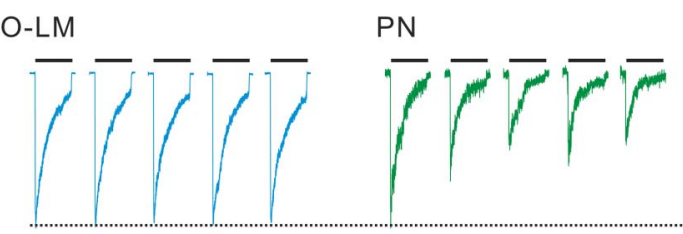

B

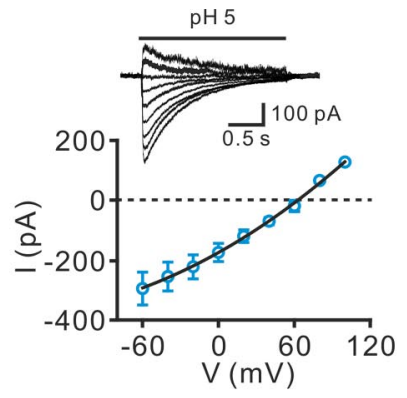

E

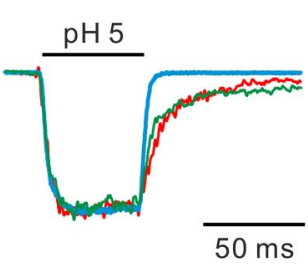

C
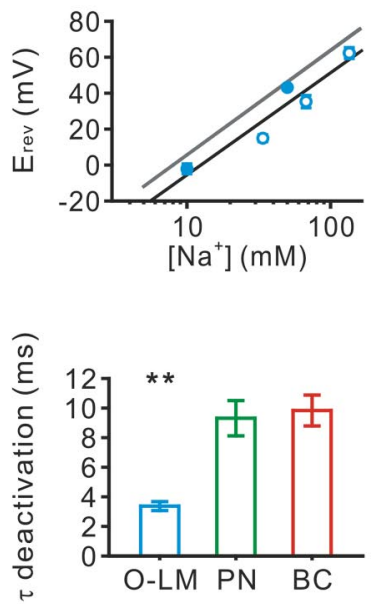

BC

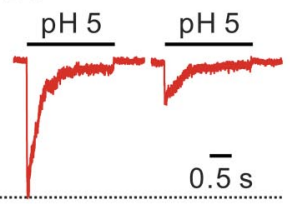

$0 . \overline{5} \mathrm{~s}$

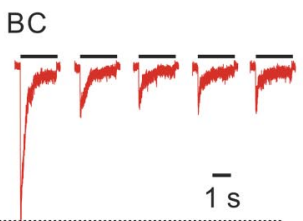

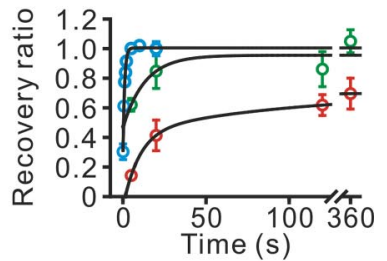

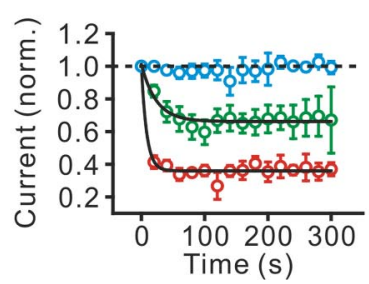

Figure 3. Functional properties of ASIC in different types of neurons. A, Inset, Representative ASIC currents in an 0-LM cell induced by pH changes from pH 7.4 to 6, 5.5, and 5. The peak current amplitude, normalized to the mean peak amplitude of pH 5 -induced currents, is plotted against the $\mathrm{pH}$ value. The continuous curve represents the single Hill equation fitted to the data points. Points represent mean values from 4 to 25 experiments. $\boldsymbol{B}$, Inset, Representative ASIC currents in a nucleated patch from an 0 -LM cell were recorded at different membrane potentials (from $-60 \mathrm{mV}$ to $+100 \mathrm{mV}$, increments $20 \mathrm{mV})$. The current-voltage $(I-V)$ curve of ASIC currents has the $E_{\text {rev }}$ of $+62 \pm 3 \mathrm{mV}$. Data points are fitted with a polynomial function. $\boldsymbol{C}$, Semilogarithmic plot of the $E_{\text {rev }}$ against $\left[\mathrm{Na}^{+}\right]_{0}$. Symbols represent the recordings in either $1.8 \mathrm{~mm}\left[\mathrm{Ca}^{2+}\right]_{0}$ (open symbols) or high $\left[\mathrm{Ca}^{2+}\right]_{0} / \mathrm{low}\left[\mathrm{Na}^{+}\right]_{0}$ (filled symbols: $100 / 10$ and $80 / 50 \mathrm{~mm}$, respectively). The gray line depicts the Nernst $\mathrm{Na}^{+}$equilibrium potential plotted against $\left[\mathrm{Na}^{+}\right]_{0}$; the black line is the linear fit of all data points. The slope values of the relationship between $E_{\text {rev }}$ and $\log \left[\mathrm{Na}{ }^{+}\right]_{0}$ correspond to 58.2 $\mathrm{mV}$ (gray) and $56.8 \mathrm{mV}$ (black) per tenfold $\left[\mathrm{Na}^{+}\right]_{0}$ change, respectively. $\boldsymbol{D}$, Left, Representative peak-scaled traces of ASIC currents showing desensitization. Right, Scatter plot of $\tau_{\text {desen }}$ of ASIC currents of 0 -LM cells $(688 \pm 97 \mathrm{~ms}, n=26)$, PNs $(471 \pm 21 \mathrm{~ms}, n=32)$ and BCs ( $434 \pm 33 \mathrm{~ms}, n=16)$. The $\tau_{\text {desen }}$ was obtained by fitting the decay phase of the current with a monoexponential function. ${ }^{* * *} p<0.0005$.E, Left, Representative peak-scaled traces of ASIC currents showing deactivation. Right, Bar plot of $\tau_{\text {deact }}$ of ASIC currents of $0-$ LM cells $(3.7 \pm 0.3 \mathrm{~ms}, n=10)$, PNs $(9.3 \pm$ $1.2 \mathrm{~ms}, n=5)$ and $\mathrm{BCs}(9.8 \pm 1.0 \mathrm{~ms}, n=5)$. The $\tau_{\text {deact }}$ was obtained by fitting the decay phase of the current with a monoexponential function. ${ }^{* *} p<0.005 . F$, Left, Representative traces showing the recovery from desensitization was measured at $-60 \mathrm{mV}$ after rapid changes from $\mathrm{pH} 7.4$ to 5 for $2 \mathrm{~s}$ and then changed back to $\mathrm{pH} 7.4$ for $20 \mathrm{~s}$, followed by a second pulse to $\mathrm{pH} 5$ for $2 \mathrm{~s}$. The peak current evoked by the second $\mathrm{pH} 5$ pulse divided by the first $\mathrm{pH} 5$ pulse was plotted against the pulse interval. Right, data points obtained from 0 -LM cells $(n=6)$, PNs $(n=16)$ and BCs $(n=9)$ were fitted with either a mono- or a biexponential function, yielding the weighted recovery time constants of $0.96 \mathrm{~s}, 13.2 \mathrm{~s}$ and $42.8 \mathrm{~s}$, respectively. G, Left, Cumulative desensitization of ASICs (at - 60 $\mathrm{mV}$ ) evoked by repetitive $2 \mathrm{~s}$ pulses (from pH 7.4 to 5) at $0.05 \mathrm{~Hz}$ in an 0 -LM, a PN and a BC, respectively. Only the first five traces were shown. Right, Time courses of onset of desensitization in 0 -LM cells $(n=6)$, PNs $(n=10)$ and BCs $(n=7)$. The peak current amplitude, normalized to the first peak current amplitude, was plotted against the time of each pulse. Curves represent exponential functions fitted to the data points. Time constants for PNs and BCs were $23.6 \pm 1.8$ and $8.3 \pm 0.3 \mathrm{~s}$, respectively.

\section{ASIC2 subunit determines the recovery of native ASICs from desensitization}

To further correlate the gating properties with gene-expression profile of individual neurons, we analyzed ASIC1a and ASIC2 subunit mRNAs of each neuron type at the single-cell level (Fig. $4 A)$. Single-cell RT-PCR analysis revealed that ASIC1a and ASIC2 mRNAs were coexpressed in CA1 PNs and O-LM cells, whereas only ASIC1a mRNA was detected in most BCs ( 9 of 11 ASIC-expressing BCs; Fig. 4B). These results correlate well with the notion that the rapid recovery of ASIC currents in O-LM cells is mediated by ASIC1a/2a heteromers, while the prolonged re- covery of ASICs from desensitization in BCs is largely attributed to the expression of ASIC1a homomers (Askwith et al., 2004). To make this point clear, we illustrated the recovery time courses of ASICs from O-LM cells (blue line) and BCs (red line) together with those of various recombinant ASICs (Fig. 4C; change to curves obtained by fitting data from Askwith et al., 2004).

PcTX1 preferentially inhibits ASIC currents in basket cells Homomeric ASIC1a channel is potently inhibited by the PcTX1 (Baron et al., 2002; Chen et al., 2005; Xiong et al., 2008). We, therefore, examined the effects of PcTX1 on functionally distinct 

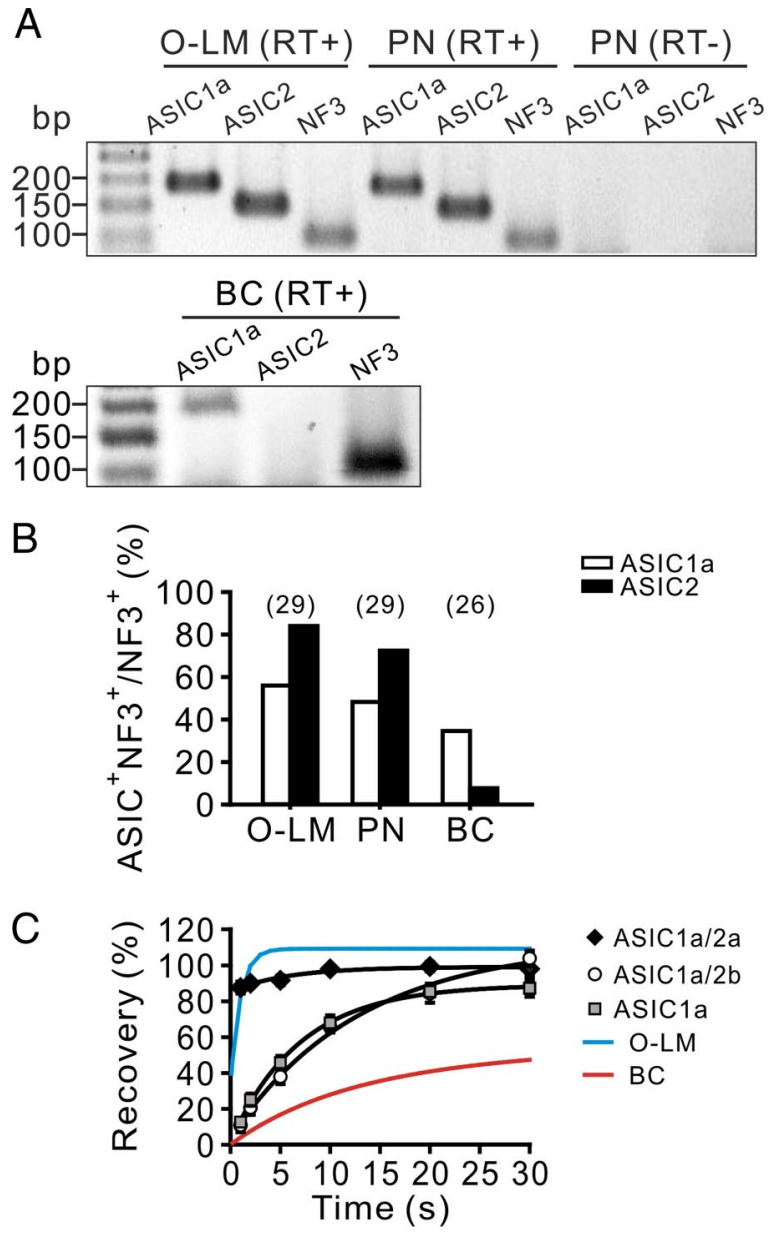

Figure 4. Expression of ASIC subunit transcripts in single hippocampal neurons. $A$, Ethidium bromide-stained gels of the PCR products amplified with primers specific for ASIC1a, ASIC2 and NF3 transcripts. Molecular weight markers were shown in the left upper and lower lanes, together with the corresponding number of base pairs. Plus and minus signs indicate samples with or without RT. All analyzed neurons expressed NF3. B, Bar graph showing the percentage of NF3-positive neurons expressing ASIC1a and ASIC2 transcripts. Number in parentheses indicates the number of the NF3-positive cells. C, Time courses of recovery from desensitization of ASICs from 0-LM cells (blue line) and BCs (red line) were plotted together with data from heterologously expressed mouse ASICs in $\mathrm{CHO}$ (change to curves obtained by fitting data from Askwith et al., 2004). Lines represent exponential functions fit to the data points.

ASIC currents in nucleated patches from either O-LM cells or BCs. Because of the very slow recovery time course $\left(\tau_{\text {recovery }}=\right.$ $42.8 \mathrm{~s}$ ) of ASICs in BCs, we thus obtained stable ASIC current amplitudes by applying short $(50 \mathrm{~ms})$ acid pulses to nucleated patches (Fig. 5). In control conditions, ASIC currents of O-LM cells and BCs showed little desensitization and were stable over time (Fig. 5, left traces). PcTX1 (30 nM) had only minimal effects on ASIC currents in nucleated patches from O-LM cells (Fig. 5, top, right). The peak current in the presence of PcTX1 was $102 \pm$ $1 \%$ of the control ( $n=4, p>0.05$; Fig. 5 , top, right). In contrast, PcTX1 (30 nM) significantly blocked $76 \pm 5 \%$ of the ASIC currents in nucleated patches from BCs $(n=6, p<0.005$; Wilcoxon signed-rank test; Fig. 5, bottom, right).

\section{ASIC channel number accounts for differences in current density}

Finally, we determined whether the remarkable differences in current densities among the neuron types were derived from differences in channel number $(N)$, maximum open probability $\left(P_{\mathrm{o}, \max }\right)$ or
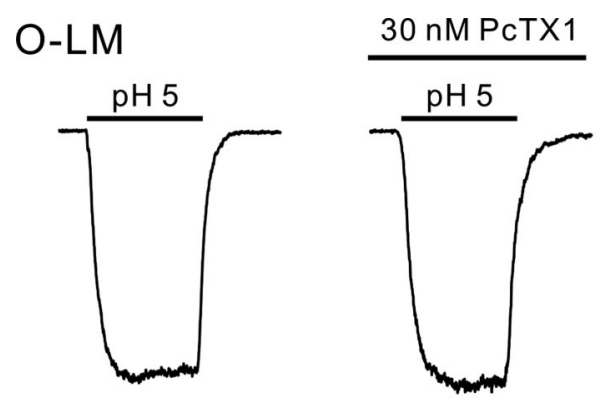

BC
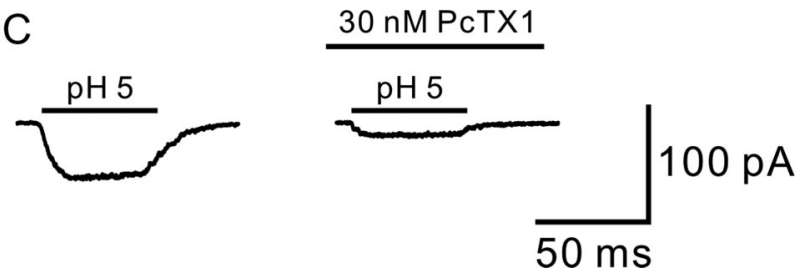

Figure 5. PCTX1 preferentially inhibited ASIC currents of BCs. Top, Traces showing ASIC currents (evoked by $\mathrm{pH} 5$ at $-100 \mathrm{mV}$ ) in a nucleated patch from an 0-LM cell in the control and in the presence of $30 \mathrm{~nm}$ PcTX1. Bottom, PcTX1 ( $30 \mathrm{~nm}$ ) inhibited 74\% of ASIC currents in a nucleated patch from a BC. Traces were average of 5-7 sweeps.

single-channel conductance $(\gamma)$. We retrieved $N, P_{\mathrm{o}, \max }$ and $\gamma$ from the ensembles of macroscopic currents (Fig. 6A) using nonstationary fluctuation analysis. The ensemble variance was calculated from the fluctuation of ASIC currents around the mean (Fig. 6B), plotted against the ensemble mean, and fitted with a parabolic function (Fig. 6C). Analysis from patches of O-LM cells yielded the $\gamma$ of $5.05 \pm 0.74 \mathrm{pS}(n=7$; Fig. $6 D)$ and the channel number $N$ of $427 \pm 82(n=7)$. For CA1 PNs, though the $\gamma$ $(6.57 \pm 1.05 \mathrm{pS}, n=7)$ was comparable to that of O-LM cells, the estimated $N$ was $69 \pm 45(n=4 ; 3$ of 7 cells were fitted with a linear function; see below), significantly less than that of O-LM cells ( $p<0.05$, Wilcoxon rank-sum test). Notably, the variancemean relation of ASIC currents from all BCs $(n=5)$ displayed a straight line rather than a parabola, indicating low open-channel probability (Alvarez et al., 2002). In this case, we can determine the $\gamma$, but not the $N$ and $P_{\mathrm{o}, \max }$ in the membrane (Alvarez et al., 2002). By fitting the data points with a linear function, we obtained the $\gamma$ of $6.29 \pm 1.75 \mathrm{pS}(n=5$; Fig. $6 D)$ from the slope. Collectively, the $\gamma$ values were not significantly different among the three groups ( $p=0.72$, Kruskal-Wallis test). Similarly, the $P \quad$ values at $\mathrm{pH} 5$ were not significantly different between O'-LM cells and CA1 PNs (O-LM cells, $0.54 \pm 0.06, n=7$ versus PNs, $0.48 \pm 0.08, n=4 ; p=0.65$, Wilcoxon rank-sum test). In sum, ASIC channel number greatly contributes to the cell typespecific difference in current density.

\section{Dendritic ASIC currents in O-LM cells are higher than those of PNs and BCs}

ASICs are distributed at somatodendrites of neurons (Wemmie et al., 2002; Alvarez de la Rosa et al., 2003; Zha et al., 2006, 2009). After filling neurons with red fluorescent dye SR101 (10 $\mu \mathrm{M})$ via somatic recording, dendrites were traced under epifluorescent microscope. Similar to somatic ASIC currents, dendritic ASIC currents of O-LM cells ( $\mathrm{V}$-clamp at $-70 \mathrm{mV}$ ) evoked by local acid puffing were transient and reversibly inhibited by amiloride $(100 \mu \mathrm{M})($ Fig. $7 A)$. Then we determined whether dendritic ASIC currents differed among three distinct types of neurons by local acid puffing along the apical dendrites of CA1 PNs (Fig. 7B), bitufted dendrites of O-LM cells (Fig. 7C) and apical dendrites of 
A

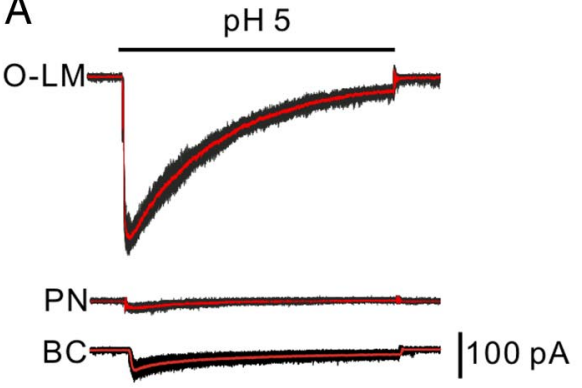

B

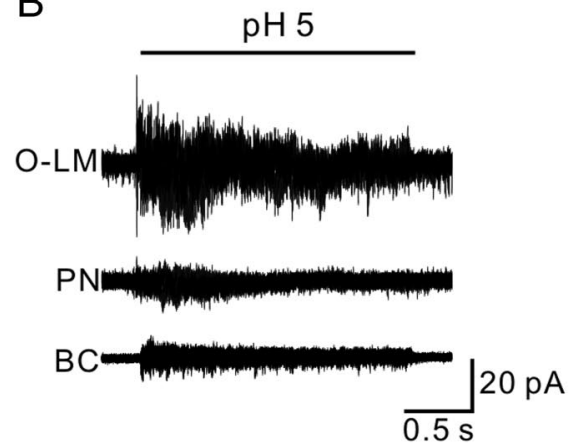

D

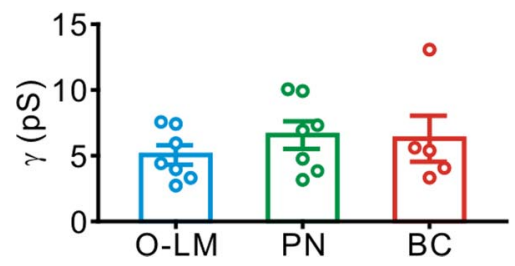

C
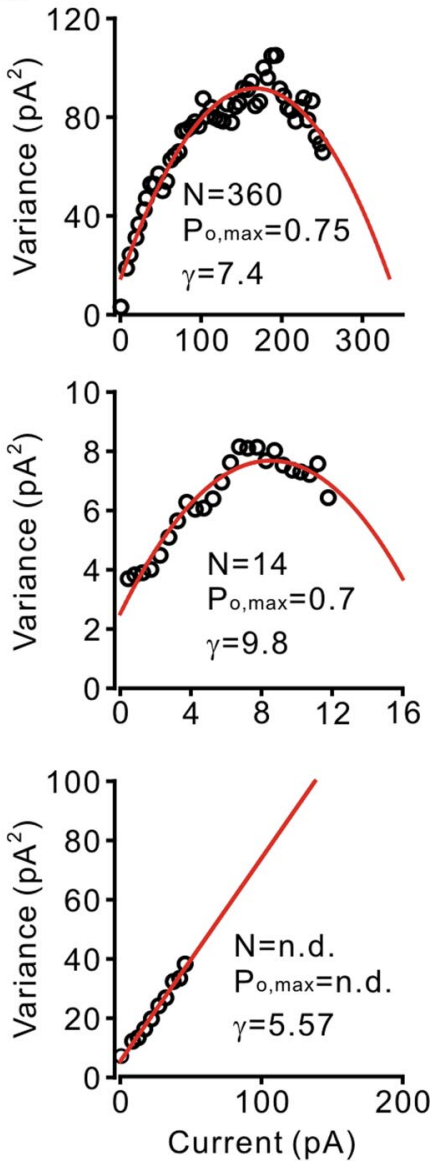

Figure 6. Nonstationary fluctuation analysis of single-channel properties of ASICs. $A$, Representative ensemble of 10 consecutive ASIC current traces (black) superimposed with the averaged current traces (red) recorded in nucleated patches from an 0-LM cell, a PN and a BC. $\boldsymbol{B}$, Traces illustrating deviation of three representative individual traces from the mean. Traces from the same cells in $\boldsymbol{A}$. $\boldsymbol{C}$, The ensemble variance was calculated from the fluctuations of ASIC currents around the mean, plotted against the ensemble mean, and fitted with a parabolic function. Each plotted point is the average of 10 sampling points. Same patches as shown in $\boldsymbol{A}$. Red curves are parabolic or linear functions fitted to the data points. $\boldsymbol{D}, \mathrm{A}$ bar plot summarizing $\gamma$ values for 0 -LM cells, PNs and $B C s$.

BCs (Fig. 7D). ASIC currents in dendrites with the puffing site at distances of 30-100 $\mu \mathrm{m}$ from the soma (280 $\pm 65 \mathrm{pA}, n=8)$ of O-LM cells are much larger than those of CA1 PNs $(132 \pm 28 \mathrm{pA}$, $n=9)$ and BCs $(52 \pm 8 \mathrm{pA}, n=6)$ (Fig. 7E). Consistently, ASIC currents effectively generated AP trains in O-LM cells when neurons were recorded in the current-clamp configuration but only caused subthreshold membrane depolarization in PNs and BCs under the same conditions (Fig. 7F).

\section{Discussion}

Earlier studies reported that GABAergic inhibitory interneurons possess larger ASIC current density than pyramidal cells in the hippocampus (Bolshakov et al., 2002; Cho and Askwith, 2008; Ziemann et al., 2008). In contrast to them, our study shows that fast-spiking, parvalbumin-expressing BCs have comparable ASIC current density to CA1 PNs. Moreover, ASIC current densities and gating greatly differ between two functionally distinct GABAergic (perisomatic versus dendritic) inhibitory interneurons. Furthermore, single-cell RT-PCR analysis reveals coexpression of ASIC1a and ASIC2 subunits in O-LM cells, whereas only ASIC1a is detected in most BCs. The lack of the ASIC2 subunit likely accounts for the prolonged recovery of native ASICs from desensitization in BCs.
Comparisons between native and recombinant ASICs

Heterologously expressed mouse ASIC1a homomers and ASIC1a/2 heteromers in CHO cells desensitize rapidly $\left(\tau_{\text {decay }}<1 \mathrm{~s}\right)$ (Askwith et al., 2004). In comparison with them, the values of $\tau_{\text {desen }}$ of native ASICs from all three cell types are $<1 \mathrm{~s}$ (Fig. 3D), suggesting that either ASICla homomers or heteromeric channels assembled by ASIC1a/2a or ASIC1a/2b combination likely mediate the majority of native channels. Further analyses of ASIC gating implicate differential expression of ASIC subunits in different cell types. Most obviously, the recovery from desensitization of ASICs is fastest in O-LM cells, intermediate in CA1 PNs and slowest in BCs (Fig. 3F). These suggest that ASIC1a/2a heteromers likely mediate ASICs of O-LM cells because the recovery from desensitization of heterologously expressed mouse ASIC1a/2a heteromers as estimated by the $\tau_{\text {recovery }}$ is $<1 \mathrm{~s}$, whereas the values of $\tau_{\text {recovery }}$ of either recombinant ASICla homomers or ASIC1a/2b heteromers are relatively slow (Fig. 4C). Conversely, the very slow recovery of ASICs from desensitization in BCs strongly suggests that the majority of ASICs in BCs is assembled as ASICla homomers. This notion is strongly supported by the results of single-cell RTPCR and pharmacological sensitivity to PcTX1.

However, differences between native and recombinant ASICs still exist, despite that the recovery time course of native ASICs qualitatively recapitulates those of heterologously expressed ASICs in $\mathrm{CHO}$ cells. First, there are quantitative differences in the recovery time course of ASICs, particularly between the native ASICs in BCs $\left(\tau_{\text {recovery }} \sim 42.8 \mathrm{~s}\right)$ and the recombinant ASIC1a homomers $\left(\tau_{\text {recovery }} \sim 7 \mathrm{~s}\right)$ (Fig. $4 C$ ). Second, recombinant mouse ASIC1a/2a heteromers generate currents that desensitize faster than ASIC1a homomers (Askwith et al., 2004). In contrast, ASICs in O-LM cells (putative "ASIC1a/2a" heteromers) significantly desensitize slower than those (putative "ASIC1a" homomers) in BCs (Fig. 3D). These could be attributed to the differences in expression systems.

The estimated values of $\gamma$ are not significantly different among the three groups. Notably, single-channel conductances of native ASICs compare well with those measured directly from unitary currents (from $4.2 \mathrm{pS}$ under $10 \mathrm{~mm}\left[\mathrm{Ca}^{2+}\right]_{\mathrm{o}}$ to $11.2 \mathrm{pS}$ under 1 $\mathrm{mm}\left[\mathrm{Ca}^{2+}\right]_{\mathrm{o}}$ ) (Immke and McCleskey, 2003). Also, the values of $P_{\mathrm{o}, \max }$ at $\mathrm{pH} 5$ are not significantly different between O-LM cells and CA1 PNs. As for BCs, analysis of cumulative desensitization reveals that desensitization of ASICs in nucleated patches of BCs develops more rapidly than those of PNs and O-LM cells during repetitive application of acid pulses (Fig. 3G). This is in agreement with the suggestion that the open probability of ASICs in BCs is relatively low by the nonstationary fluctuation analysis. 
A O-LM $\mathrm{pH} 4.5$

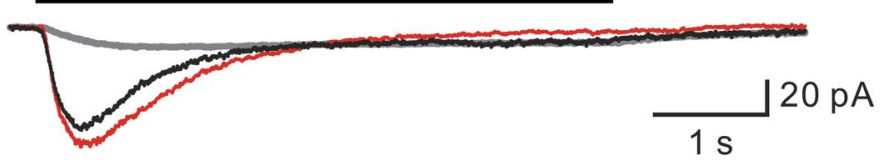

B

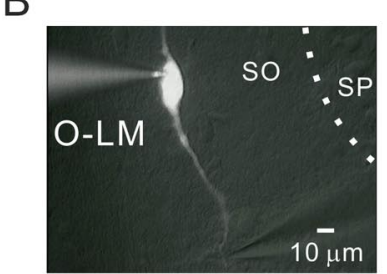

C

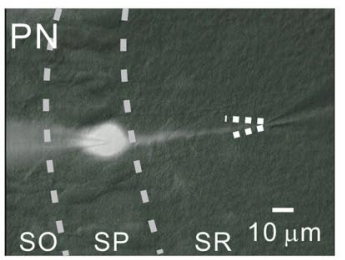

D

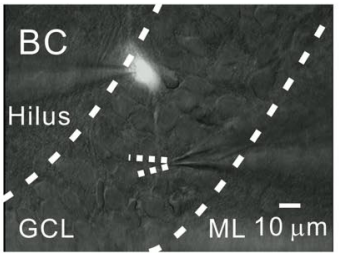

$\mathrm{pH} 4$
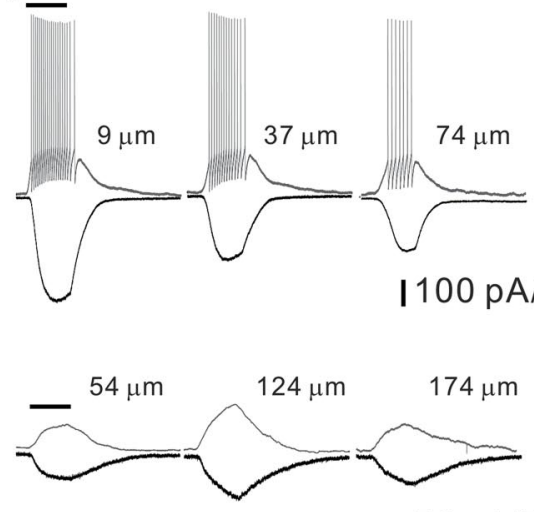

$150 \mathrm{pA} / 5 \mathrm{mV}$

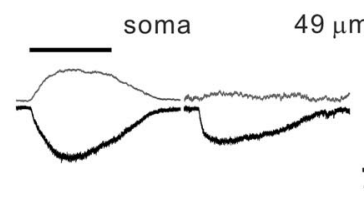

$\frac{\mathrm{s}}{1 \mathrm{~s}} \mathrm{pA} / 5 \mathrm{mV}$

\section{E}
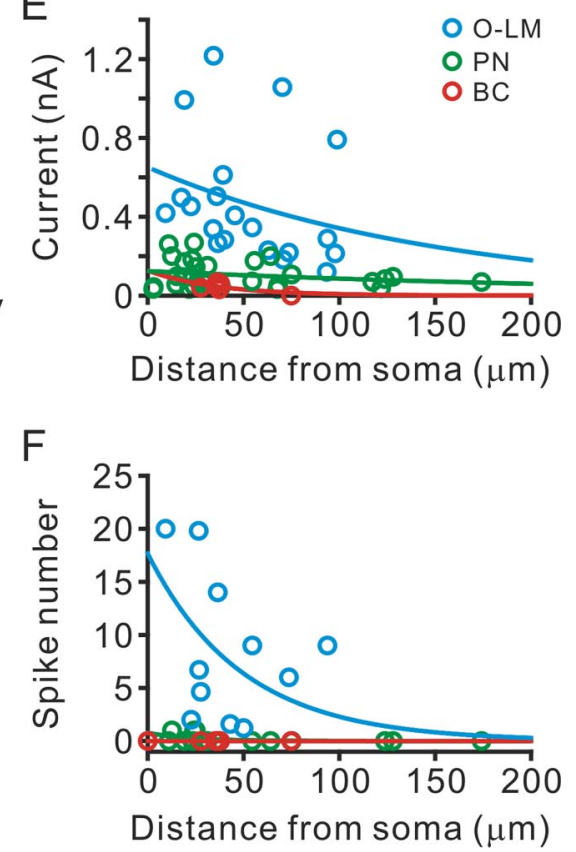

Figure 7. Dendritic ASIC currents in distinct types of neurons. $\boldsymbol{A}$, Focal acid puffs ( $5 \mathrm{~s}, \mathrm{pH} 4.5$ ) to the 0 -LM cell dendrite (at the distance of $23 \mu \mathrm{m}$ from the soma) evoked a desensitizing inward current, which was reversibly blocked by amiloride (100 $\mu \mathrm{m}$ ). Black, Control; gray, amiloride; red, washout. B, Left, An 0-LM cell filled with SR101 via somatic recording; the puff pipette was placed near the dendrite. Right, Brief acid puffs (1 s, pH 4) at different distances along the 0 -LM dendrite evoked large inward currents at the voltage-clamp potential (V-clamp) of - 70 mV and spike trains in the current-clamp recording (holding potential $-70 \mathrm{mV}$ ), respectively. C, Left, A PN filled with SR101 and the puff pipette was placed near the apical dendrite. Right, Brief acid puffs (1 s, pH 4) at different distances along the PN dendrite evoked relatively smaller inward currents (V-clamp $=-70 \mathrm{mV}$ ) and subthreshold membrane depolarization in the current-clamp recording (holding potential $-70 \mathrm{mV}$ ), respectively. D, Left, A BC filled with SR101 and the puff pipette was placed near the apical dendrite. Right, Local acid puffs (2 s, pH 4) evoked relatively smaller ASIC currents $(\mathrm{V}$-clamp $=-70 \mathrm{mV}$ ) and subthreshold membrane depolarization in the current-clamp recording (holding potential $-70 \mathrm{mV}$ ), respectively. $\boldsymbol{E}$, ASIC currents as a function of distance from the soma. Lines represent exponential functions fit to the data points. Data are from 80 -LM cells, 9 PNs and 6 BCs. F, Summary plot of spike number plotted against distance from the soma. Lines represent exponential functions fit to data points. Data are from 80 -LM cells, 9 PNs and 6 BCs. All experiments were performed in the presence of $1 \mathrm{mM}$ kynurenic acid and $1 \mu \mathrm{M}$ SR95531.

\section{Possible functions of ASICs in perisomatic and dendritic inhibitory interneurons}

Although our understanding of interneuron heterogeneity is still far from being complete, a major dichotomy in the inhibitory control of pyramidal cells has already been established (Freund and Katona, 2007). Dendritic inhibitory interneurons (for instance, O-LM cells) are responsible for the control of the efficacy and plasticity of glutamatergic inputs from specific sources that terminate in the same dendritic domain (Miles et al., 1996). On the other hand, perisomatic inhibitory interneurons (for instance, BCs) control the output of pyramidal cells (Miles et al., 1996). In addition, several intrinsic properties (see Introduction of this study) of these two major types of interneurons are found to be very different. In this study, we uncover the expression of ASICs as a novel cell type-specific property which might underlie their differences in synaptic transmission and relative susceptibility to brain injury.

Several lines of evidence suggest that ASICs play crucial roles in synaptic transmission. First, long-term potentiation, a form of synaptic plasticity underlying learning and memory, is abrogated at Schaffer collateral-CA1 pyramidal cell synapses in ASIC1a knock-out mice (Wemmie et al., 2002). Second, presynaptic re- lease probability is increased in hippocampal neurons from ASIC1a knock-out mice (Cho and Askwith, 2008). Finally, ASICs interact with several postsynaptic scaffolding proteins such as PSD-95, PICK1 and CaMKII (for review, see Wemmie et al., 2006). More recently, ASIC2 subunits, but not ASIC1a subunits, were shown to target ASICs to the synapse via an association with PSD-95 and loss of ASIC2 subunits decreases the percentage of spines responding to acid (Zha et al., 2009). Interestingly, our results demonstrate that ASIC2 subunit mRNAs were not detected in most BCs and relatively small ASIC currents were detected in BC dendrites. Thus, subunit composition of ASICs in different types of GABAergic inhibitory interneurons might also contribute to cell type-specific long-term plasticity at glutamatergic synapses onto hippocampal interneurons (Nissen et al., 2010).

Deletion of ASIC1a gene was shown to increase the presynaptic release probability and led to paired-pulse depression at the hippocampal glutamatergic synapses (Cho and Askwith, 2008). Conversely, overexpression of ASIC1a subunits in ASIC1a knock-out neurons increases paired-pulse ratio. Thus, relative abundance of ASICs might underlie the heterogeneity of GABAergic inhibitory outputs (Maccaferri et al., 2000). Intrigu- 
ingly, consistent with this notion, we found a similar correlation between the functional ASIC current and the release probability of interneurons. In this study, BCs with relatively low ASIC expression have high release probability and exhibit paired-pulse depression at short interspike intervals (Kraushaar and Jonas, 2000; Maccaferri et al., 2000). On the contrary, O-LM cells with relatively high ASIC expression have low release probability and show no paired-pulse modulation. (Maccaferri et al., 2000).

\section{Functional implications}

Interneurons exhibit differential susceptibility to injury by epileptic insults that are accomplished by transient acidification (Morin et al., 1998; Cossart et al., 2001; Wittner et al., 2001, 2005). In experimental epilepsy, dendrite-targeting interneurons, such as O-LM cells, selectively degenerate, leading to "disinhibition" in dendritic compartments of PNs. In contrast, soma-targeting interneurons, mainly BCs, are relatively spared, resulting in enhanced somatic inhibition (Cossart et al., 2001; Wittner et al., 2005). Increasing studies showed that neurons lacking ASICs are resistant to ischemic/acid injury (Xiong et al., 2004; Gao et al., 2005; Wemmie et al., 2006). Our data show that $\mathrm{BCs}$, in contrast to O-LM cells and other non-fast-spiking interneurons, have strikingly low-density and rapidly desensitizing ASICs. Furthermore, BCs have relatively low input resistance $(\sim 134 \mathrm{M} \Omega$, see Results) compared with O-LM cells $(\sim 336 \mathrm{M} \Omega)$. Consequently, relatively large ASIC currents in O-LM cells during transient acidification together with the high input resistance will lead to membrane depolarization and firing of O-LM cells (Fig. 7). Thus, acidification can preferentially induce firing of O-LM cells accompanied by massive $\mathrm{Ca}^{2+}$ influx via voltagegated $\mathrm{Ca}^{2+}$ channels and thereby might have a greater impact on $\mathrm{O}$-LM cells than BCs. Interestingly, in addition to the unique ASIC expression feature, fast-spiking BCs have very efficient $\mathrm{Ca}^{2+}$ buffer capacity (Aponte et al., 2008). Quantitatively, the magnitude of $\mathrm{Ca}^{2+}$ binding ratio $\left(\kappa_{\mathrm{s}}\right)$ of BCs $\left(\kappa_{\mathrm{s}} \sim 200\right.$; Aponte et al., 2008) is tenfold larger than that of O-LM cells $\left(\kappa_{\mathrm{s}} \sim 20\right.$; Liao and Lien, 2009). Together, all these factors likely contribute to selective degeneration of O-LM cells and disinhibition of pyramidal cell dendrites induced by experimental epilepsy.

\section{Perspectives}

Our results point to the cell type-specific expression of ASICs in hippocampal GABAergic inhibitory microcircuits and the findings demonstrate how the distribution and proportions of ASIC subunits vary in different cells under physiological conditions. Our work provides a better understanding of how acidosis in the hippocampus could influence the network and how hippocampal acidosis might suppress seizure activity. A challenge of future studies will be to delete ASIC gene in a cell type-restricted manner to address the meaning of differential expression of ASICs in the brain.

\section{References}

Alvarez de la Rosa D, Krueger SR, Kolar A, Shao D, Fitzsimonds RM, Canessa CM (2003) Distribution, subcellular localization and ontogeny of ASIC1 in the mammalian central nervous system. J Physiol 546:77-87.

Alvarez O, Gonzalez C, Latorre R (2002) Counting channels: a tutorial guide on channel fluctuation analysis. Adv Physiol Educ 26:327-341.

Aponte Y, Lien CC, Reisinger E, Jonas P (2006) Hyperpolarizationactivated cation channels in fast-spiking interneurons of rat hippocampus. J Physiol 574:229-243.

Aponte Y, Bischofberger J, Jonas P (2008) Efficient $\mathrm{Ca}^{2+}$ buffering in fastspiking basket cells of rat hippocampus. J Physiol 586:2061-2075.

Askwith CC, Wemmie JA, Price MP, Rokhlina T, Welsh MJ (2004) Acid- sensing ion channel 2 (ASIC2) modulates ASIC1 $\mathrm{H}^{+}$-activated currents in hippocampal neurons. J Biol Chem 279:18296-18305.

Baron A, Waldmann R, Lazdunski M (2002) ASIC-like, proton-activated currents in rat hippocampal neurons. J Physiol 539:485-494.

Bolshakov KV, Essin KV, Buldakova SL, Dorofeeva NA, Skatchkov SN, Eaton MJ, Tikhonov DB, Magazanik LG (2002) Characterization of acidsensitive ion channels in freshly isolated rat brain neurons. Neuroscience 110:723-730.

Chen X, Kalbacher H, Gründer S (2005) The Tarantula toxin psalmotoxin 1 inhibits acid-sensing ion channel (ASIC) 1a by increasing its apparent $\mathrm{H}^{+}$ affinity. J Gen Physiol 126:71-79.

Cho JH, Askwith CC (2008) Presynaptic release probability is increased in hippocampal neurons from ASIC1 knockout mice. J Neurophysiol 99:426-441.

Cobb SR, Buhl EH, Halasy K, Paulsen O, Somogyi P (1995) Synchronization of neuronal activity in hippocampus by individual GABAergic interneurons. Nature 378:75-78.

Coryell MW, Wunsch AM, Haenfler JM, Allen JE, Schnizler M, Ziemann AE, Cook MN, Dunning JP, Price MP, Rainier JD, Liu Z, Light AR, Langbehn DR, Wemmie JA (2009) Acid-sensing ion channel-1a in the amygdala, a novel therapeutic target in depression-related behavior. J Neurosci 29:5381-5388.

Cossart R, Dinocourt C, Hirsch JC, Merchan-Perez A, De Felipe J, Ben-Ari Y, Esclapez M, Bernard C (2001) Dendritic but not somatic GABAergic inhibition is decreased in experimental epilepsy. Nat Neurosci 4:52-62.

Du J, Zhang L, Weiser M, Rudy B, McBain CJ (1996) Developmental expression and functional characterization of the potassium-channel subunit $\mathrm{Kv} 3.1 \mathrm{~b}$ in parvalbumin-containing interneurons of the rat hippocampus. J Neurosci 16:506-518.

Efron B, Tibshirani RJ (1998) An introduction to the bootstrap. London: Chapman and Hall/CRC.

Engel D, Jonas P (2005) Presynaptic action potential amplification by voltage-gated $\mathrm{Na}^{+}$channels in hippocampal mossy fiber boutons. Neuron 45:405-417.

Freund TF, Buzsáki G (1996) Interneurons of the hippocampus. Hippocampus 6:347-470.

Freund TF, Katona I (2007) Perisomatic inhibition. Neuron 56:33-42.

Gao J, Duan B, Wang DG, Deng XH, Zhang GY, Xu L, Xu TL (2005) Coupling between NMDA receptor and acid-sensing ion channel contributes to ischemic neuronal death. Neuron 48:635-646.

Gentet LJ, Stuart GJ, Clements JD (2000) Direct measurement of specific membrane capacitance in neurons. Biophys J 79:314-320.

Hartveit E, Veruki ML (2007) Studying properties of neurotransmitter receptors by nonstationary noise analysis of spontaneous postsynaptic currents and agonist-evoked responses in outside-out patches. Nat Protoc 2:434-448

Hille B (2001) Ion channels of excitable membranes, Ed 3. Sunderland, MA: Sinauer.

Immke DC, McCleskey EW (2003) Protons open acid-sensing ion channels by catalyzing relief of $\mathrm{Ca}^{2+}$ blockade. Neuron 37:75-84.

Jonas P, Bischofberger J, Fricker D, Miles R (2004) Interneuron diversity series: fast in, fast out-temporal and spatial signal processing in hippocampal interneurons. Trends Neurosci 27:30-40.

Klausberger T, Somogyi P (2008) Neuronal diversity and temporal dynamics: the unity of hippocampal circuit operations. Science 321:53-57.

Klausberger T, Magill PJ, Márton LF, Roberts JD, Cobden PM, Buzsáki G, Somogyi P (2003) Brain-state- and cell-type-specific firing of hippocampal interneurons in vivo. Nature 421:844-848.

Koh DS, Geiger JR, Jonas P, Sakmann B (1995) $\mathrm{Ca}^{2+}$-permeable AMPA and NMDA receptor channels in basket cells of rat hippocampal dentate gyrus. J Physiol 485:383-402.

Kraushaar U, Jonas P (2000) Efficacy and stability of quantal GABA release at a hippocampal interneuron-principal neuron synapse. J Neurosci 20:5594-5607.

Liao CW, Lien CC (2009) Estimating intracellular $\mathrm{Ca}^{2+}$ concentrations and buffering in a dendritic inhibitory hippocampal interneuron. Neuroscience 164:1701-1711.

Lien CC, Jonas P (2003) Kv3 potassium conductance is necessary and kinetically optimized for high-frequency action potential generation in hippocampal interneurons. J Neurosci 23:2058-2068.

Lien CC, Martina M, Schultz JH, Ehmke H, Jonas P (2002) Gating, modu- 
lation and subunit composition of voltage-gated $\mathrm{K}^{+}$channels in dendritic inhibitory interneurones of rat hippocampus. J Physiol 538:405-419.

Liss B, Roeper J (2004) Correlating function and gene expression of individual basal ganglia neurons. Trends Neurosci 27:475-481.

Maccaferri G, Roberts JD, Szucs P, Cottingham CA, Somogyi P (2000) Cell surface domain specific postsynaptic currents evoked by identified GABAergic neurones in rat hippocampus in vitro. J Physiol 524:91-116.

Markram H, Toledo-Rodriguez M, Wang Y, Gupta A, Silberberg G, Wu C (2004) Interneurons of the neocortical inhibitory system. Nat Rev Neurosci 5:793-807.

Martina M, Schultz JH, Ehmke H, Monyer H, Jonas P (1998) Functional and molecular differences between voltage-gated $\mathrm{K}^{+}$channels of fastspiking interneurons and pyramidal neurons of rat hippocampus. J Neurosci 18:8111-8125.

Mazzuca M, Heurteaux C, Alloui A, Diochot S, Baron A, Voilley N, Blondeau N, Escoubas P, Gélot A, Cupo A, Zimmer A, Zimmer AM, Eschalier A, Lazdunski M (2007) A tarantula peptide against pain via ASIC1a channels and opioid mechanisms. Nat Neurosci 10:943-945.

McBain CJ, Fisahn A (2001) Interneurons unbound. Nat Rev Neurosci 2:11-23.

Miles R, Tóth K, Gulyás AI, Hájos N, Freund TF (1996) Differences between somatic and dendritic inhibition in the hippocampus. Neuron 16:815823.

Morin F, Beaulieu C, Lacaille JC (1998) Selective loss of GABA neurons in area $\mathrm{CA} 1$ of the rat hippocampus after intraventricular kainate. Epilepsy Res 32:363-369.

Nissen W, Szabo A, Somogyi J, Somogyi P, Lamsa KP (2010) Cell typespecific long-term plasticity at glutamatergic synapses onto hippocampal interneurons expressing either parvalbumin or CB1 cannabinoid receptor. J Neurosci 30:1337-1347.

Pouille F, Scanziani M (2004) Routing of spike series by dynamic circuits in the hippocampus. Nature 429:717-723.

Sík A, Hájos N, Gulácsi A, Mody I, Freund TF (1998) The absence of a major $\mathrm{Ca}^{2+}$ signaling pathway in GABAergic neurons of the hippocampus. Proc Natl Acad Sci U S A 95:3245-3250.
Stuart GJ, Dodt HU, Sakmann B (1993) Patch-clamp recordings from the soma and dendrites of neurons in brain slices using infrared video microscopy. Pflugers Arch 423:511-518.

Waldmann R, Champigny G, Bassilana F, Heurteaux C, Lazdunski M (1997) A proton-gated cation channel involved in acid-sensing. Nature 386:173-177.

Wemmie JA, Chen J, Askwith CC, Hruska-Hageman AM, Price MP, Nolan BC, Yoder PG, Lamani E, Hoshi T, Freeman JH Jr, Welsh MJ (2002) The acid-activated ion channel ASIC contributes to synaptic plasticity, learning and memory. Neuron 34:463-477.

Wemmie JA, Price MP, Welsh MJ (2006) Acid-sensing ion channels: advances, questions and therapeutic opportunities. Trends Neurosci 29:578-586.

Wittner L, Maglóczky Z, Borhegyi Z, Halász P, Tóth S, Eross L, Szabó Z, Freund TF (2001) Preservation of perisomatic inhibitory input of granule cells in the epileptic human dentate gyrus. Neuroscience 108:587-600.

Wittner L, Eross L, Czirják S, Halász P, Freund TF, Maglóczky Z (2005) Surviving CA1 pyramidal cells receive intact perisomatic inhibitory input in the human epileptic hippocampus. Brain 128:138-152.

Xiong ZG, Zhu XM, Chu XP, Minami M, Hey J, Wei WL, MacDonald JF, Wemmie JA, Price MP, Welsh MJ, Simon RP (2004) Neuroprotection in ischemia: blocking calcium-permeable acid-sensing ion channels. Cell 118:687-698.

Xiong ZG, Pignataro G, Li M, Chang SY, Simon RP (2008) Acid-sensing ion channels (ASICs) as pharmacological targets for neurodegenerative diseases. Curr Opin Pharmacol 8:25-32.

Zha XM, Wemmie JA, Green SH, Welsh MJ (2006) Acid-sensing ion channel la is a postsynaptic proton receptor that affects the density of dendritic spines. Proc Natl Acad Sci U S A 103:16556-16561.

Zha XM, Costa V, Harding AM, Reznikov L, Benson CJ, Welsh MJ (2009) ASIC2 subunits target acid-sensing ion channels to the synapse via an association with PSD-95. J Neurosci 29:8438-8446.

Ziemann AE, Schnizler MK, Albert GW, Severson MA, Howard MA 3rd, Welsh MJ, Wemmie JA (2008) Seizure termination by acidosis depends on ASIC1a. Nat Neurosci 11:816-822. 